\title{
Ketamine-Induced Exacerbation of Psychotic Symptoms and Cognitive Impairment in Neuroleptic-Free Schizophrenics
}

Anil K. Malhotra, M.D., Debra A. Pinals, M.D., Caleb M. Adler, M.D., Igor Elman, M.D., Allan Clifton, B.A., David Pickar, M.D., and Alan Breier, M.D.

The N-methyl-d-aspartate (NMDA) receptor has been implicated in the pathophysiology of schizophrenia. We administered subanesthetic doses of the NMDA receptor antagonist ketamine in a double-blind, placebo-controlled design to 13 neuroleptic-free schizophrenic patients to investigate if schizophrenics will experience an exacerbation of psychotic symptoms and cognitive impairments with ketamine. We also examined whether schizophrenics experienced quantitative or qualitative differences in ketamine response in comparison to normal controls. Schizophrenics experienced a brief ketamine-induced exacerbation of positive and negative symptoms with further decrements in recall and recognition memory. They also displayed greater ketamine-induced impairments in free recall than normals. Qualitative differences included auditory hallucinations and paranoia in patients but not in normals. These data indicate that ketamine is associated with exacerbation of core psychotic and cognitive symptoms in schizophrenia. Moreover, ketamine may differentially affect cognition in schizophrenics in comparison to normal controls. [Neuropsychopharmacology 17:141-150, 1997] (C) 1997 American College of Neuropsychopharmacology. Published by Elsevier Science Inc.
KEY WORDS: Ketamine; NMDA; Schizophrenia; Cognition; Psychosis

Pharmacological, post-mortem and clinical studies have implicated the glutamatergic N-methyl-d-aspartate (NMDA) receptor in the pathophysiology of schizophrenia (Olney et al. 1995; Javitt and Zukin 1991). The most frequently cited evidence for an NMDA receptor hypothesis of schizophrenia are reports from the 1950s investigating the effects of phenylcyclidine (PCP), a potent non-competitive NMDA receptor antagonist, in

From the Experimental Therapeutics Branch, Intramural Research Program, National Institute of Mental Health, National Institutes of Health, Bethesda, Maryland.

Address correspondence to: Anil K. Malhotra, M.D., Experimental Therapeutics Branch, National Institute of Mental Health, Building 10, Room 4N212, 10 Center Drive, Bethesda, Maryland 208921380 .

Received September 6, 1996; revised January 10, 1997; accepted February 13, 1997. normal volunteers and schizophrenia subjects (Javitt and Zukin 1991). These reports indicated that normal individuals administered subanesthetic doses of PCP demonstrated neuropsychological and behavioral psychopathology similar to that observed in schizophrenia (Davies and Beech 1960; Luby et al. 1959; Cohen et al. 1962; Rosenbaum et al. 1959) while acutely PCP-intoxicated individuals were virtually indistinguishable from symptomatic schizophrenic patients (Allen and Young 1978). In addition, schizophrenic patients administered PCP were commonly reported to experience prolonged exacerbations of psychotic symptoms resembling the acute phase of their illness (Luby et al. 1959; Ban et al. 1961).

Placebo-controlled, double-blind studies of the effects of NMDA antagonists in humans have been limited. Potent NMDA antagonists such as PCP and MK-801 produce neuropathological changes in rat brain (Olney et al. 1989) while PCP use has been associated with pro- 
longed psychotic episodes in humans (Allen and Young 1978). Recently, however, administration of subanesthetic doses of the "dissociative" anesthetic ketamine has provided a useful strategy to examine NMDA function in human subjects (Krystal et al. 1994; Lahti et al. 1995; Malhotra et al. 1996). Ketamine, like PCP, binds to a site in the ion channel of the NMDA receptor with approximately 1/10th the potency of PCP (Anis et al. 1983). Clinically, ketamine produces minimal cardiac and respiratory effects while its anesthetic and behavioral effects remit soon after administration (Pandit et al. 1980; Moretti et al. 1984). Unlike PCP, ketamine has not been associated with long-term adverse sequelae despite extensive use as an anesthetic agent (Schorn and Whitman 1980).

Subanesthetic doses of ketamine produce behavioral symptoms and cognitive deficits in normal volunteers that resemble some symptoms of schizophrenia (Krystal et al. 1994; Malhotra et al. 1996). For instance, ketamine induces a syndrome in normals consisting of thought disorder, perceptual abnormalities, blunted affect, emotional withdrawal, and explicit memory impairment. Ketamine, however, does not consistently produce auditory hallucinations in normals and causes other symptoms (i.e., temporal and spatial distortions) not commonly observed in schizophrenia. These data suggest that ketamine's effects in normals are similar, although not identical, to previous reports of PCPinduced psychosis in normals and may provide a clinical model for some aspects of schizophrenia.

There is limited data on ketamine's effects in schizophrenic patients. If ketamine, like PCP, exacerbates core psychotic and cognitive symptoms of schizophrenia, this would provide further evidence that the NMDA receptor may play a role in the pathophysiology of schizophrenia. Lahti et al. (1995), however, have reported that bolus doses of ketamine did not significantly increase Brief Psychiatric Rating Scale (BPRS) psychosis subscale ratings in 6 neuroleptic-free schizophrenics, although haloperidol-treated subjects were noted to experience increases in BPRS psychosis ratings. Ketamine's effect on cognition was not examined in this patient group. In addition, it is not known if schizophrenic patients have a different quantitative (i.e., a greater magnitude of response in specific symptoms with ketamine) or qualitative (i.e., alterations in different behavioral or cognitive measures) ketamine response than normal controls.

We have examined the effects of a placebo-controlled, double-blind, one hour infusion of subanesthetic doses of ketamine on behavior and cognition in neurolepticfree schizophrenic patients and normal volunteers. The hypothesis to be tested was that neuroleptic-free schizophrenics would experience an exacerbation of psychotic symptoms and further decrements in cognitive performance during ketamine administration. Moreover, we examined the ketamine response of neuroleptic-free schizophrenics and normal volunteers to determine if neuroleptic-free schizophrenics experienced quantitative or qualitative differences in ketamine response in comparison to normal controls.

\section{METHODS}

\section{Subjects}

Thirteen patients (mean age $=31.3 \pm 2.8$ years, 10 males, 3 females) meeting DSM-III-R criteria for schizophrenia or schizo-affective disorder as determined by structured diagnostic interview [Structured Clinical Interview for DSM-III-R (SCID) (Spitzer et al. 1990)] were admitted to the 4-East Patient Care Unit of the Clinical Center of the National Institutes of Health (NIH), Bethesda, Maryland and participated in the study after giving written informed consent to a NIMH IRB approved protocol. As part of a double-blind, placebocontrolled study of antipsychotic drugs, all subjects underwent ketamine infusion after being neuroleptic-free for at least two weeks (Table 1). One patient was neuroleptic-naive at time of entry into the study. No benzodiazepines, chloral hydrate or other psychotropic medications were administered during this protocol.

Sixteen normal volunteers (mean age $=27.8 \pm 1.9,12$ males, 4 females) were recruited through the NIH normal volunteer program and participated in the study. All subjects were free of psychiatric disorders as determined by structured diagnostic interview. This study group overlaps with a previous report examining the cognitive effects of ketamine in normal volunteers (Malhotra et al. 1996).

All subjects were in good physical health as determined by physical exam, electrocardiogram, laboratory testing including liver and thyroid function tests, and urinalysis, and had been free of drug and alcohol abuse for at least six months.

\section{Procedure}

Each subject participated in two double-blind test days: one involving ketamine infusion and the other a placebo (saline) infusion. The order of ketamine and placebo was randomized and test days were separated by at least one day. Subjects fasted after midnight on each study day. On the morning of each study day, bilateral antecubital intravenous lines were inserted. Sixty minutes after IV placement, a bolus of $0.12 \mathrm{mg} / \mathrm{kg}$ of ketamine or placebo was administered followed by infusion of $0.65 \mathrm{mg} / \mathrm{kg}$ of ketamine (maximum dose of 58 $\mathrm{mg}$ ) or placebo over one hour for a total dose of 0.77 $\mathrm{mg} / \mathrm{kg} / \mathrm{hr}$ in subjects receiving ketamine. This dose was selected after consultation with the NIH anesthesia department and dose-finding pilot studies in normal 
Table 1. Clinical Characteristics of Schizophrenics in Ketamine Infusion Study

\begin{tabular}{|c|c|c|c|c|c|c|}
\hline Subject & Age & Sex & Age of Onset & $\begin{array}{c}\begin{array}{c}\text { Number } \\
\text { of Prior }\end{array} \\
\text { Hospitalizations }\end{array}$ & $\begin{array}{l}\text { Total Months } \\
\text { Hospitalization }\end{array}$ & $\begin{array}{c}\text { Days } \\
\text { Neuroleptic-Free }\end{array}$ \\
\hline 1 & 23 & $\mathrm{M}$ & 20 & 1 & 2.3 & 25 \\
\hline 2 & 49 & $\mathrm{~F}$ & 40 & 7 & 3.5 & 14 \\
\hline 3 & 22 & $\mathrm{M}$ & 21 & 1 & 1.0 & 20 \\
\hline 4 & 23 & $\mathrm{~F}$ & 20 & 2 & 2.0 & 20 \\
\hline 5 & 22 & $\mathrm{M}$ & 19 & 5 & 2.0 & 18 \\
\hline 6 & 40 & $\mathrm{~F}$ & 26 & 6 & 2.5 & 22 \\
\hline 7 & 21 & $\mathrm{M}$ & 20 & 1 & 4.0 & 16 \\
\hline 8 & 38 & $\mathrm{M}$ & 37 & 3 & 2.0 & $a$ \\
\hline 9 & 45 & M & 23 & 12 & 15.0 & 14 \\
\hline 10 & 31 & $\mathrm{M}$ & 28 & 1 & 0.8 & 79 \\
\hline 11 & 37 & $\mathrm{M}$ & 25 & 2 & 2.0 & 16 \\
\hline 12 & 26 & $\mathrm{M}$ & 25 & 3 & 1.0 & 16 \\
\hline 13 & 30 & $\mathrm{M}$ & 23 & 4 & 1.0 & 39 \\
\hline $\begin{array}{l}\text { Mean } \\
\quad( \pm \text { S.E.M. })\end{array}$ & $31.3 \pm 2.8$ & & $25.2 \pm 1.9$ & $3.7 \pm 0.9$ & $3.0 \pm 1.1$ & $24.9 \pm 5.3$ \\
\hline
\end{tabular}

${ }^{a}$ neuroleptic naive.

volunteers to minimize sedative, cardiac, and respiratory effects.

\section{Behavioral and Cognitive Measures}

Baseline cognitive and behavioral assessments were performed 30 minutes prior $(-30)$ to the infusion. Behavioral ratings were collected at $+10,+35,+55,+90$, and +120 minutes of each infusion day. Cognitive testing was conducted at timepoints $+10,+55,+90$, and +120 minutes.

Symptoms were assessed with the 18 item BPRS (Overall and Gorham 1962). The BPRS scores were analyzed in total and by analysis of the empirically derived factors for thought disturbance, withdrawal-retardation, hostility-suspiciousness, and anxiety-depression.

Cognitive testing included tasks that assessed attention, free recall of categorically related words, and recognition memory for categorically related words. These tasks have been standardized and validated in studies of the effects of different classes of drugs in a number of patient populations (Weingartner et al. 1982, 1983a, 1983b, 1992). Subjects were read a list of 12 categorically-related words at a 2 second rate. These words are typical exemplars of categories such as vegetables, fruit, and animals. Six of the twelve words were read once and six of the words were repeated after the presentation of at least two other words. The subjects were instructed to listen to the words and identify when a word was repeated by saying "repeat." To accomplish this task, subjects must be able to attend to the words and hold them in working memory for as long as 34 seconds. After an activity-filled two minute delay during which behavioral measures were collected, subjects were asked to freely recall all words. After a 30 second activity-filled delay, subjects were then read a new list of 24 words from the same category. This list contained all 12 of the previous words and 12 distractor items. Subjects were asked to identify the origin of each as "new" (not on previous list) or "old" (on previous list).

\section{Data Analysis}

To test the hypothesis that schizophrenics experience exacerbations of psychotic symptoms and cognitive deficits, repeated-measures analyses of variance (ANOVAs) with time and drug condition (ketamine versus placebo) as the two within-subject factors were conducted. Post-hoc Newman-Keuls t-tests were conducted when the ANOVA drug $\times$ time interactions were significant. To determine if schizophrenics have a greater magnitude of response to ketamine than normal volunteers, a three-way ANOVA was conducted with diagnosis as the grouping factor, and drug condition and time as the within-subject factors. Post-hoc Newman-Keuls t-tests were conducted when the ANOVA drug condition $x$ time $\times$ diagnosis interactions were significant. All ANOVAs were interpreted with the Greenhouse-Geisser conservative F-test in order to account for sphericity. No adjustments were made for multiple comparisons given the limited number of statistical tests that were used. Qualitative aspects of ketamine response in schizophrenics and controls were descriptively assessed with clinical observations, self-reports and exploratory t-tests of individual BPRS items.

Pearson correlational coefficients were conducted between the changes in cognitive scores and the changes in BPRS scores (total score and individual factors) at the 
time of peak drug effect ( +55 minutes). All correlations were two-tailed.

\section{RESULTS}

\section{Neuroleptic-Free Schizophrenic Patients}

Behavioral Effects. In neuroleptic-free schizophrenic patients, ketamine produced significant effects on BPRS scores (Table 2). In the repeated measures ANOVA of BPRS total score, the effects of drug $(\mathrm{F}(1,12)=17.44, \mathrm{p}=$ $.001, \epsilon=1.0)$, time $(\mathrm{F}(5,60)=8.70, \mathrm{p}<.001, \epsilon=0.51)$ and the interaction of drug condition and time $(\mathrm{F}(5,60)=$ 22.38, $\mathrm{p}<.0001, \epsilon=0.52)$ were significant. Post-hoc analyses revealed that ketamine produced significantly higher BPRS scores at +10 minutes $(\mathrm{p}=.0001),+35$ minutes $(\mathrm{p}=.0001)$ and +55 minutes $(\mathrm{p}=.0001)$ compared to placebo.

BPRS factors were examined to characterize the behavioral response to ketamine. The ANOVA of the BPRS thought disturbance factor revealed that effects of $\operatorname{drug}(\mathrm{F}(1,12)=37.25, \mathrm{p}=.0001, \epsilon=1.0)$, time $(\mathrm{F}(5,60)=$ 20.17, $\mathrm{p}<.0001, \epsilon=0.59)$ and the interaction of drug and time $(\mathrm{F}(5,60)=17.20, \mathrm{p}<.0001, \epsilon=0.49)$ were highly significant. Post-hoc analyses showed that ketamine produced higher thought disturbance scores at +10 minutes $(\mathrm{p}=.0001),+35$ minutes $(\mathrm{p}=.0001)$ and +55 minutes $(\mathrm{p}=.0001)$ than placebo. For withdrawalretardation, the effect of time $(\mathrm{F}(5,60)=3.74, \mathrm{p}=.024, \epsilon$ $=0.54)$ and the interaction of drug and time $(F(5,60)=$ $5.31, \mathrm{p}=.007, \epsilon=0.49)$ were significant. Significant differences were found between ratings at the $+10(p=$

Table 2. Ketamine Effects on BPRS Scores ${ }^{d}$ in Neuroleptic-Free Schizophrenics $(n=13)$ and Normal Volunteers $(N=16)$

\begin{tabular}{|c|c|c|c|c|c|c|}
\hline & -30 & +10 & +55 & +120 & $\mathbf{F}^{a}$ & $\mathrm{p}^{b}$ \\
\hline \multicolumn{7}{|l|}{ BPRS Total } \\
\hline \multicolumn{7}{|c|}{ Schizophrenics } \\
\hline Ketamine & $33.5 \pm 2.5$ & $37.8 \pm 2.5^{c}$ & $40.1 \pm 2.9^{c}$ & $32.9 \pm 2.3$ & \multirow{2}{*}{22.4} & \multirow{2}{*}{$<0.001$} \\
\hline Placebo & $34.3 \pm 2.7$ & $32.4 \pm 2.4$ & $31.9 \pm 2.4$ & $32.8 \pm 2.4$ & & \\
\hline \multicolumn{7}{|l|}{ Volunteers } \\
\hline Ketamine & $19.3 \pm 0.4$ & $25.6 \pm 0.9^{c}$ & $27.1 \pm 1.6^{c}$ & $19.3 \pm 0.5$ & \multirow{2}{*}{29.2} & \multirow{2}{*}{$<0.001$} \\
\hline Placebo & $19.1 \pm 0.6$ & $19.0 \pm 0.4$ & $18.7 \pm 0.4$ & $18.5 \pm 0.3$ & & \\
\hline \multicolumn{7}{|c|}{ Thought Disturbance } \\
\hline \multicolumn{7}{|c|}{ Schizophrenics } \\
\hline Ketamine & $6.8 \pm 0.8$ & $9.3 \pm 1.1^{c}$ & $10.2 \pm 1.0^{c}$ & $7.2 \pm 0.8$ & \multirow{2}{*}{17.2} & \multirow{2}{*}{$<0.001$} \\
\hline Placebo & $6.9 \pm 0.9$ & $6.8 \pm 0.8$ & $6.9 \pm 0.8$ & $7.2 \pm 0.9$ & & \\
\hline \multicolumn{7}{|l|}{ Volunteers } \\
\hline Ketamine & $3.0 \pm 0.0$ & $5.3 \pm 0.3^{c}$ & $6.1 \pm 0.6^{c}$ & $3.3 \pm 0.1$ & \multirow{2}{*}{24.3} & \multirow{2}{*}{$<0.001$} \\
\hline Placebo & $3.0 \pm 0.0$ & $3.1 \pm 0.1$ & $3.0 \pm 0.0$ & $3.0 \pm 0.0$ & & \\
\hline \multicolumn{7}{|c|}{ Hostility-Suspiciousness } \\
\hline \multicolumn{7}{|c|}{ Schizophrenics } \\
\hline Ketamine & $5.1 \pm 0.7$ & $5.2 \pm 0.6$ & $5.5 \pm 0.7$ & $4.6 \pm 0.6$ & \multirow{2}{*}{2.2} & \multirow{2}{*}{0.11} \\
\hline Placebo & $4.6 \pm 0.6$ & $4.2 \pm 0.3$ & $4.0 \pm 0.3$ & $4.2 \pm 0.4$ & & \\
\hline \multicolumn{7}{|l|}{ Volunteers } \\
\hline Ketamine & $3.3 \pm 0.2$ & $3.3 \pm 0.1$ & $3.5 \pm 0.5$ & $3.1 \pm 0.1$ & \multirow{2}{*}{0.48} & \multirow{2}{*}{0.53} \\
\hline Placebo & $3.1 \pm 0.1$ & $3.1 \pm 0.1$ & $3.1 \pm 0.1$ & $3.1 \pm 0.1$ & & \\
\hline \multicolumn{7}{|c|}{ Withdrawal-Retardation } \\
\hline \multicolumn{7}{|c|}{ Schizophrenics } \\
\hline Ketamine & $7.6 \pm 0.7$ & $9.2 \pm 0.8^{d}$ & $9.8 \pm 0.8^{d}$ & $7.8 \pm 0.6$ & \multirow{2}{*}{5.3} & \multirow{2}{*}{0.007} \\
\hline Placebo & $8.6 \pm 0.7$ & $8.6 \pm 0.7$ & $8.5 \pm 0.8$ & $8.9 \pm 0.8$ & & \\
\hline \multicolumn{7}{|l|}{ Volunteers } \\
\hline Ketamine & $3.3 \pm 0.1$ & $6.3 \pm 0.5^{c}$ & $6.5 \pm 0.6^{c}$ & $3.6 \pm 0.3$ & \multirow{2}{*}{14.2} & \multirow{2}{*}{$<0.001$} \\
\hline Placebo & $3.3 \pm 0.1$ & $3.5 \pm 0.3$ & $3.5 \pm 0.2$ & $3.2 \pm 0.1$ & & \\
\hline Anxiety-Depre & & & & & & \\
\hline Schizophreni & & & & & & \\
\hline Ketamine & $5.0 \pm 0.6$ & $4.6 \pm 0.4$ & $4.9 \pm 0.6$ & $4.6 \pm 0.6$ & & \\
\hline Placebo & $5.0 \pm 0.6$ & $4.6 \pm 0.6$ & $4.4 \pm 0.6$ & $4.5 \pm 0.6$ & 0.3 & 0.76 \\
\hline Volunteers & & & & & & \\
\hline Ketamine & $3.4 \pm 0.2$ & $3.6 \pm 0.2$ & $3.8 \pm 0.3$ & $3.1 \pm 0.1$ & 27 & 0 \\
\hline Placebo & $3.3 \pm 0.1$ & $3.2 \pm 0.1$ & $3.1 \pm 0.1$ & $3.1 \pm 0.1$ & 2.7 & 0.06 \\
\hline
\end{tabular}

${ }^{a}$ Mean \pm S.E.M

${ }^{b}$ Drug $\times$ Time

${ }^{c} \mathrm{p}<0.05$ (versus placebo)

${ }^{d} \mathrm{p}<0.05$ (versus baseline) 
$.02),+35(\mathrm{p}=.014)$ and the $+55(\mathrm{p}=.0007)$ minute timepoints and baseline ( -30 minutes) ratings during the ketamine infusion day, but no significant differences were seen between ketamine and placebo at the six timepoints. Ketamine did not significantly affect hostility-suspiciousness (drug $\times$ time $=\mathrm{F}(5,60)=2.19$, $\mathrm{p}=.114, \epsilon=0.54$ ) or anxiety-depression ratings (drug $\times$ time $=\mathrm{F}(5,60)=0.35, \mathrm{p}=0.76, \epsilon=0.52)$.

Cognitive Effects. In neuroleptic-free schizophrenics, ketamine produced significant decreases in free recall and recognition memory (Figure 1, panel A). For free recall, the effects of drug $(\mathrm{F}(1,12)=14.49, \mathrm{p}=.0025, \epsilon=$ 1.0) time $(\mathrm{F}(4,48)=6.16, \mathrm{p}=.001, \epsilon=0.84)$ and the interaction of drug and time $(\mathrm{F}(4,48)=8.86, \mathrm{p}<.001, \epsilon=$ $0.69)$ were significant. Post-hoc analyses demonstrated that ketamine produced significant decreases in free recall at +10 minutes $(\mathrm{p}=.0006)$, and +55 minutes $(\mathrm{p}=$ .0003) compared to placebo. For recognition memory, the effects of drug $(\mathrm{F}(1,12)=8.45, \mathrm{p}=.013, \epsilon=1.0)$ time $(\mathrm{F}(4,48)=6.83, \mathrm{p}=.001, \epsilon=0.7)$ and the interaction of drug and time $(\mathrm{F}(4,48)=5.91, \mathrm{p}=.003, \epsilon=0.69)$ were significant. Post-hoc analyses revealed that ketamine produced significant decreases in recognition memory at +10 minutes $(\mathrm{p}=.0002)$ and +55 minutes $(\mathrm{p}=.004)$ compared to placebo. Ketamine did not have a significant effect on attention (drug $\times$ time $=\mathrm{F}(4,48)=1.44$, $\mathrm{p}=.25, \epsilon=0.72)$.

There were no significant correlations between the ketamine-induced changes in any of the cognitive measures with ketamine-induced changes in BPRS ratings. Change in free recall was significantly correlated with change in recognition memory $(\mathrm{r}=.56, \mathrm{p}=.05)$.

\section{Ketamine Effects in Neuroleptic-Free Schizophrenics versus Normal Volunteers}

Behavioral Effects. The behavioral effects of ketamine in normal volunteers were consistent with our previous report and are summarized in Table 2. Ketamine produced significant increases in BPRS total score (drug $\times$ time $=F(5,75)=29.22, \mathrm{p}<.0001, \epsilon=0.36)$ at $+10 \mathrm{~min}-$ utes $(\mathrm{p}=.0001),+35$ minutes $(\mathrm{p}=.0002)$ and $+55 \mathrm{~min}$ utes $(\mathrm{p}=.0002)$ compared to placebo. Examination of BPRS factors revealed significant ketamine effects on the BPRS thought disturbance factor (drug $\times$ time $=$ $\mathrm{F}(5,75)=24.28, \mathrm{p}<.0001, \epsilon=0.47)$ and withdrawalretardation $($ drug $\times$ time $=\mathrm{F}(5,75)=14.19, \mathrm{p}<.0001$, $\epsilon=0.56)$ during ketamine compared to placebo. Ketamine did not have significant effects on anxiety-depression $($ drug $\times$ time $=\mathrm{F}(5,75)=2.69, \mathrm{p}=.06, \epsilon=0.58)$ or hostility-suspiciousness $($ drug $\times$ time $=F(5,75)=0.48, \mathrm{p}=$ $.53, \epsilon=0.23$ ) in normal volunteers.

Comparison of ketamine effects on behavior between normal volunteers and schizophrenic patients was conducted with a three-way ANOVA with diagno- sis as the grouping factor. Analysis of BPRS total score did not reveal a significant interaction between drug condition, time, and diagnosis $(\mathrm{F}(5,135)=0.22$, $\mathrm{p}=$ $0.87, \epsilon=0.58$ ). ANOVA of the BPRS factors did not reveal significant three-way interactions for thought disturbance $(F(5,135)=0.28, \mathrm{p}=0.84, \epsilon=0.58)$, withdrawal-retardation $(\mathrm{F}(5,135)=.045, \mathrm{p}=0.72, \epsilon=0.6)$, hostility-suspiciousness $(\mathrm{F}(5,135)=1.35, \mathrm{p}=0.26, \epsilon=$ $0.63)$, or anxiety-depression $(\mathrm{F}(5,135)=0.31, \mathrm{p}=0.82$, $\epsilon=0.61$.

Cognitive Effects. Cognitive effects of ketamine in normal volunteers were consistent with our previous report and are summarized in Figure 1 (panel B). Ketamine produced significant decreases in free recall $($ drug $\times$ time $=\mathrm{F}(4,60)=5.35, \mathrm{p}=.002, \epsilon=0.81)$ and recognition memory (drug $\times$ time $=\mathrm{F}(4,56)=11.05$, $\mathrm{p}<.0001, \epsilon=0.68)$ at +10 and +55 minutes compared to placebo. For attention, ketamine did not have a significant effect on the interaction of drug and time $(\mathrm{F}(4,60)=$ $2.32, \mathrm{p}=.09, \epsilon=0.69$ ).

There were no significant correlations between the ketamine-induced changes in any of the cognitive measures with ketamine-induced changes in BPRS ratings in normal volunteers. Change in free recall was significantly correlated with change in recognition memory $(r=$ $.56, \mathrm{p}=.03)$.

Comparison of ketamine effects on cognition between normal volunteers and schizophrenic patients was conducted with a three-way ANOVA. A significant interaction between diagnosis $\times$ drug $\times$ time was observed for free recall $(F(4,108)=2.52, p=0.05, \epsilon=$ $0.88)$. Covariance for age of the subjects did not significantly affect the diagnosis $\times$ drug $\times$ time interaction $(\mathrm{F}(4,108)=2.52, \mathrm{p}=0.05)$. Normal volunteers had higher free recall during ketamine administration than schizophrenics during ketamine administration at +10 minutes $(\mathrm{p}=.0004)$ and +55 minutes $(\mathrm{p}=.07)$. There were not significant differences between schizophrenic and normal volunteer free recall scores at +10 minutes $(\mathrm{p}=0.12)$ and +55 minutes $(\mathrm{p}=0.35)$ during the placebo condition. Schizophrenic free recall scores decreased $63.5 \%$ from baseline to +10 minutes of ketamine infusion whereas normal volunteers free recall scores decreased $33.3 \%$. There was not a significant diagnosis $\times$ drug $\times$ time interaction upon analysis of ketamine effects on attention $(\mathrm{F}(4,108)=0.41, \mathrm{p}=0.78, \epsilon=0.86)$ or recognition memory $(\mathrm{F}(4,104)=1.39, \mathrm{p}=0.25, \epsilon=0.73)$.

Clinical Observations. Qualitative analysis of ketamine response revealed that certain clinical phenomena were commonly observed in neuroleptic-free schizophrenics and in normal volunteers. Most subjects noted perceptual abnormalities such as feelings of "time is slowed down" and "my body feels funny-like it's changing shape." Moreover, both groups commonly reported 

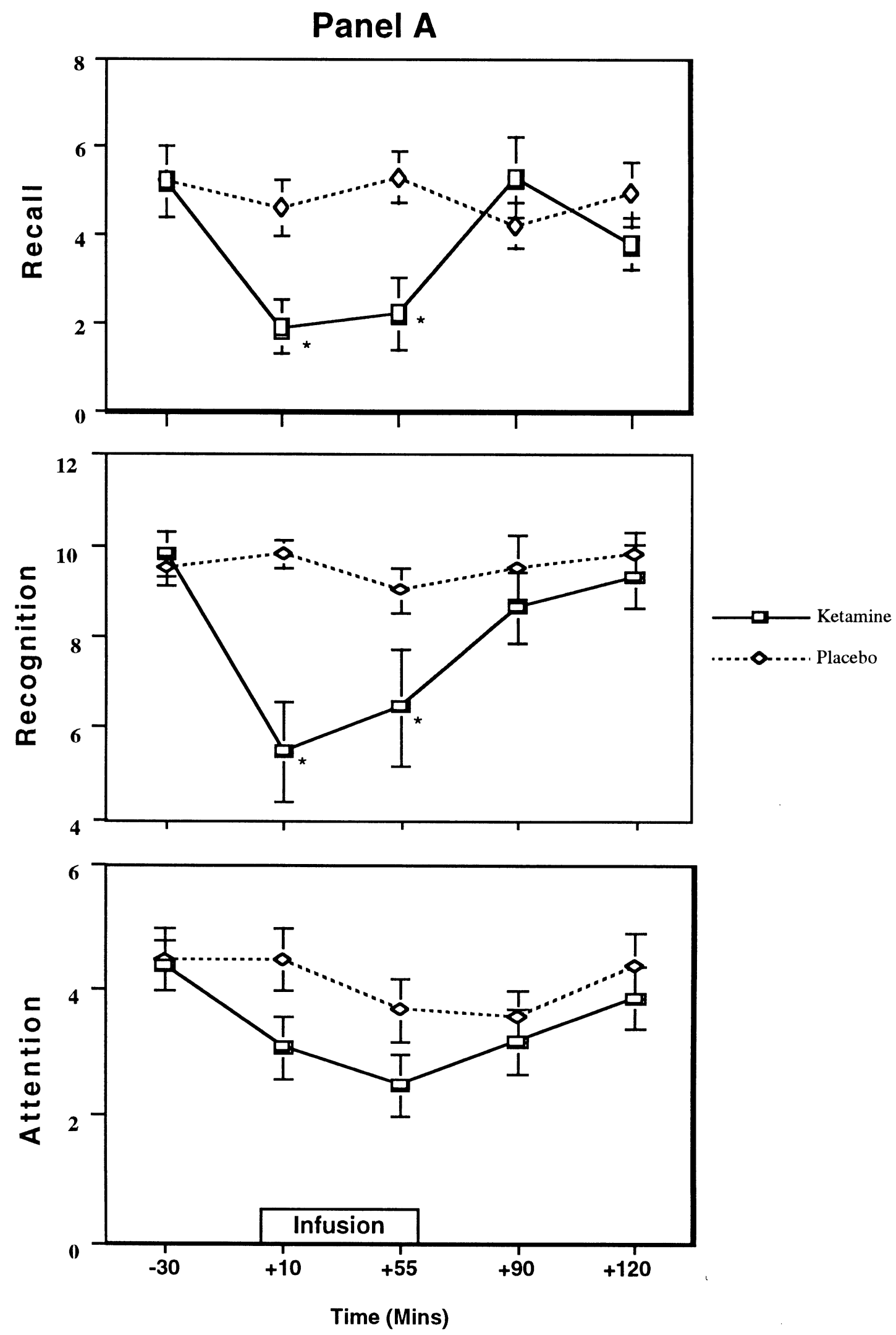

Figure 1. Ketamine effects on cognition in 13 neuroleptic-free schizophrenics (Panel A) and 16 normal volunteers (Panel B) 


\section{Panel B}
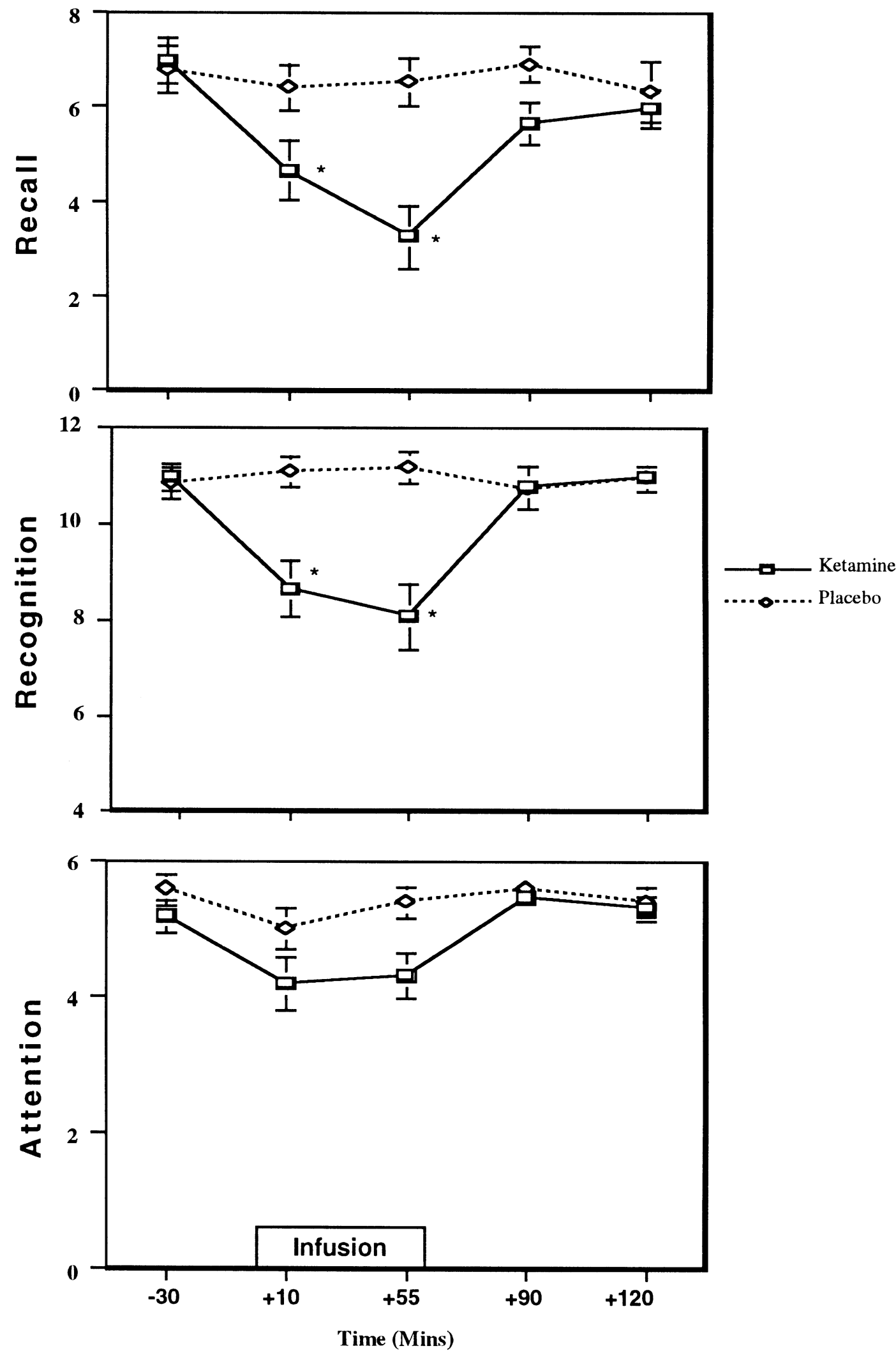

Figure 1. Continued 
that their thoughts were increasingly disorganized"difficult to put thoughts into words" - as evidenced by increased conceptual disorganization ratings in 12 of the 13 patients $\left(X_{\text {baseline }}=2.4, X_{\text {ket }(+55)}=4.2, \mathrm{p}<.001\right)$ and in 13 of the 16 normal volunteers $\left(X_{\text {baseline }}=1.0\right.$, $\left.\mathrm{X}_{\text {ket }(+55)}=2.8, \mathrm{p}<.001\right)$.

Differences in ketamine response were observed with auditory hallucinations and paranoid symptoms. In schizophrenics, ketamine was associated with a recreation of some patient's acute psychotic symptomatology. Eight of our 13 patients had a documented history of auditory hallucinations. Of these 8 patients, 4 noted ketamine-induced hallucinations despite not actively hallucinating prior to the study $\left(X_{\text {baseline }}=2.3\right.$, $\left.\mathrm{X}_{\mathrm{ket}(+55)}=2.9, \mathrm{p}=.09\right)$. One patient noted a return of auditory hallucinations with "same as I always hear"referring to characteristic auditory hallucinations of two voices commenting on his actions in a derogatory fashion. Of the 5 patients without a prior history of auditory hallucinations, none reported ketamine-induced hallucinations $\left(X_{\text {baseline }}=1.2, X_{\text {ket }(+55)}=1.4, \mathrm{p}=.37\right)$. Eight of our 13 patients had a documented history of paranoid symptomatology. Of these 8 patients, 6 were observed to become more suspicious during ketamine $\left(X_{\text {baseline }}=3.0, X_{\text {ket }(+55)}=3.4, \mathrm{p}=.08\right)$ compared to 1 of the 5 patients without a prior history of paranoia $\left(\mathrm{X}_{\text {baseline }}=1.4, \mathrm{X}_{\mathrm{ket}}\left(+_{55}\right)=1.6, \mathrm{p}=.70\right)$. Two subjects who prior to the study were extremely withdrawn and psychomotorically retarded became mute for a large portion of the infusion and appeared to be responding continuously to internal stimuli. After the infusion, one of these subjects revealed that he had "heard voices all the way through" and believed that the staff was talking about him outside the treatment room. These observations suggest that ketamine can re-activate schizophrenics' individual symptoms and is not simply creating new psychotic symptoms in schizophrenics.

In contrast to the schizophrenics, none of the normal volunteers reported onset of auditory hallucinations with ketamine $\left(X_{\text {baseline }}=1.0, X_{\text {ket }(+55)}=1.3, \mathrm{p}=.10\right)$. Moreover, only one normal volunteer was noted to become suspicious during the ketamine infusion $\left(X_{\text {baseline }}=\right.$ $\left.1.0, X_{\text {ket }(+55)}=1.2, \mathrm{p}=.33\right)$. Finally, all of our normal volunteers continued to interact with the examiner during the ketamine infusion despite the frequent occurrence of withdrawal and blunted affect.

\section{DISCUSSION}

This study demonstrated that ketamine significantly exacerbated psychotic symptoms and cognitive impairment in neuroleptic-free schizophrenic patients. Ketamine increased ratings on measures of positive symptoms and negative symptoms and impaired the patient's ability to recall and recognize recently presented material. Ket- amine did not alter ratings of anxiety or mood and did not significantly impair the patient's attentional function. In comparison to the normal volunteer response to ketamine, neuroleptic-free schizophrenics displayed significantly greater impairments in free recall during ketamine administration but no quantitative differences were found upon analysis of BPRS ratings. However, qualitative differences such as increases in auditory hallucinations and paranoia were observed in schizophrenics with histories of these symptoms, but not in normal controls.

Our data demonstrating exacerbation of schizophrenic symptomatology is consistent with previous observations of $\mathrm{PCP}^{\prime} \mathrm{s}$ effects in schizophrenia. Luby et al. (1959) noted an intensification of thought disorder in four chronic schizophrenic patients administered low doses of PCP. Ban et al. (1961) reported that two schizophrenic patients underwent a re-emergence of their original psychotic state. As noted in the clinical observations, many of our patients also reported a re-activation of individual psychotic symptoms with increased auditory hallucinations in $50 \%$ of our patients with a prior history of hallucinations, and increased suspiciousness in $75 \%$ of the patients with prior history of paranoid symptoms.

Our data contrasts with a previous report of ketamine response in schizophrenia (Lahti et al. 1995). In 5 neuroleptic-free schizophrenics, Lahti et al. (1995) found that BPRS total score only showed a trend ( $\mathrm{p}=$ 0.07 ) towards increasing without significant changes in positive symptoms after a bolus dose of $0.5 \mathrm{mg} / \mathrm{kg}$ of ketamine. We find highly significant increases in BPRS total score and in positive symptoms throughout exposure to ketamine. These contrasting data might be accounted for by differences in study design, patient selection, method of ketamine administration (bolus versus infusion) and ketamine dosage in the two studies.

Ketamine also significantly impaired neurolepticfree schizophrenic patients' free recall of recently presented items and decreased their ability to recognize the origin of these items. These effects were quite dramatic as measured by the low scores that schizophrenics displayed during ketamine administration. As a group, patients only recalled 2 of 12 words that were presented two minutes earlier and could only recognize the origin of 6 of 12 words. As subjects are only asked to identify the origin of a word as "old" or "new," 6 correct of a possible 12 equals a recognition memory score predicted by chance.

We also found a differential ketamine response between neuroleptic-free schizophrenics and normal volunteers on performance of the free recall cognitive task. Neuroleptic-free schizophrenics had greater ketamineinduced decrements in free recall during ketamine administration than did normal volunteers. As free recall and recognition memory performance were correlated 
in both normals and schizophrenics, it was unexpected that there was not a differential ketamine response in recognition memory performance. This lack of a differential recognition memory response, however, may have been due to a "floor effect" as the patients' mean recognition memory score of approximately 50\% during ketamine administration equals that expected by chance alone. Therefore, the schizophrenics could not have performed any more poorly on this task resulting in a potential blunting of ketamine-induced recognition memory impairment in the schizophrenic group. Perhaps use of a less demanding recognition task would have identified differences between the normal volunteer and schizophrenic ketamine response.

In consideration of our data, it is important to note that although we find differential quantitative differences in ketamine-induced cognitive impairment between schizophrenics and controls, we did not find a differential quantitative ketamine response in analysis of BPRS ratings. Some caveats should be considered in the interpretation of these data.

First, our analytic methods may have blurred the potential distinction between schizophrenic and normal volunteer ketamine response. In general, the normal volunteers" ratings changed from ratings of "no symptoms" to ratings in the "mild" ranges of psychopathology during ketamine administration while the schizophrenics began with "mild" ratings and progressed to ratings in the "severe" ranges. The neurobiological events underlying these rating changes may be quite different from each other and we may be minimizing fundamentally different responses by simply comparing the magnitude of ketamine response between the two groups. Second, higher baseline BPRS scores in schizophrenics than in normals may have resulted in a "ceiling effect" in schizophrenic BPRS ratings during ketamine administration as ratings approached the higher range of scores on certain individual items for some schizophrenics but not in normals. Third, the size of our study group may have resulted in insufficient power to detect quantitatively small behavioral differences in ketamine response. Alternatively, our data may simply suggest that schizophrenics' psychotic symptoms may not be differentially affected by ketamine in comparison to normal controls.

Another consideration in the interpretation of our data is the possibility that ketamine produces its behavioral and cognitive effects via other, non-NMDA, neurotransmitter systems. However, ketamine's affinity for the intrachannel site within the NMDA receptor is several-fold higher than its affinities for monoamine transporter sites (Smith et al. 1981), the sigma receptor (Oye et al. 1991), the mu opiate receptor (Smith et al. 1980), and acetylcholinesterase (Cohen et al. 1974). Moreover, opiate, cholinergic, and monoamine receptor antagonists do not block ketamine and PCP-induced behavioral ef- fects (Byrd et al. 1987), indirect evidence that ketamine's behavioral effects are mediated by its interaction with the PCP site. In vitro studies have found that ketamine only reduces non-NMDA voltage-gated potassium currents at concentrations much higher than reported in patients anesthetized with ketamine (Rothman 1988). This suggests that low doses of ketamine enhance selectivity for the PCP site.

Finally, the dosage of ketamine used in this study must be considered as dose-dependent effects of ketamine and other NMDA antagonists on brain metabolism have been reported. In rodents, low doses of ketamine produce a laminar pattern of increased metabolic activity while higher doses produce more homogeneous effects. (Crosby et al. 1982; Hammer and Herkenham 1983). Moreover, one study has reported that PCP increases glucose utilization in superficial layers of the frontal cortex whereas higher doses reduce glucose utilization in this region (Weissman et al. 1987). Lower doses of ketamine also increase glucose utilization in limbic cortex with more marked increases associated with higher doses (Crosby et al. 1982; Hammer and Herkenham 1983). Therefore, although our data demonstrates significantly increased psychotic symptoms and impaired cognition with low doses of ketamine, it remains possible that higher, yet still subanesthetic, doses of ketamine may produce a somewhat different spectrum of behavioral and cognitive effects in schizophrenics and normal controls.

In summary, we find that ketamine, an NMDA antagonist, exacerbates the psychotic symptoms and cognitive deficits of neuroleptic-free schizophrenics. Ketamine produces greater levels of positive symptoms, negative symptoms and impairments in cognitive function. Moreover, we observed qualitative behavioral differences in ketamine response and quantitative differences in ketamine-induced cognitive deficits between normals and schizophrenics. These double-blind and placebo-controlled data may therefore provide support for the hypothesis that NMDA receptor dysfunction is involved in some aspects of the pathophysiology of schizophrenia.

\section{ACKNOWLEDGMENTS}

The authors thank John J. Bartko for consultation with the statistical analyses, the staff of the 4East Nursing Unit for providing expert clinical care, and Marilyn Duncan for editorial assistance.

\section{REFERENCES}

Allen RM, Young SJ (1978): Phencyclidine-induced psychosis. Am J Psychiatry 135:1081-1084 
Anis NA, Berry SC, Burton NR, Lodge D (1983): The dissociative anaesthetics, ketamine and phencyclidine, selectively reduce excitation of central mammalian neurones by N-methyl-aspartate. Br J Pharmacol 79:565-575

Ban TA, Lohrenz JJ, Lehmann HE (1961): Observations on the action of sernyl-a new psychotropic drug. Can J Psychiatry 6:150-157

Byrd LD, Standish LJ, Howell LL (1987): Behavioral effects of phencyclidine and ketamine alone and in combination with other drugs. Eur J Pharmacol 144:331-341

Cohen BD, Rosenbaum G, Luby ED, Gottlieb JS (1962): Comparison of phenylcyclidine hydrochloride (Sernyl) with other drugs. Arch Gen Psychiatry 6:395-397

Cohen ML, Chan SL, Bhargava HN, Trevor AJ (1974): Inhibition of mammalian brain acetylcholinesterase by ketamine. Biochem Pharmacol 23:1647-1652

Crosby G, Crane AM, Sokoloff L (1982): Local changes in cerebral glucose utilization during ketamine anesthesia. Anesthesiologist 56:437-443

Davies BM, Beech HR (1960): The effect of 1-arylcyclohexylamine (Sernyl) on twelve normal volunteers. J Ment Sci 106:912-924

Hammer RP, Herkenham M (1983): Altered metabolic activity in the cerebral cortex of rats exposed to ketamine. J Comp Neurol 220:396-404

Javitt DC, Zukin SR (1991): Recent advances in the phencyclidine model of schizophrenia. Am J Psychiatry 148: 1301-1308

Krystal JH, Karper LP, Seibyl JP, Freeman GK, Delaney R, Bremner JD, Heninger GR, Bowers Jr MB, Charney DS (1994): Subanesthetic effects of the noncompetitive NMDA antagonist, ketamine, in humans: psychotomimetic, perceptual, cognitive, and neuroendocrine responses. Arch Gen Psychiatry 51:199-214

Lahti AC, Koffel B, LaPorte D, Tamminga CA (1995): Subanesthetic doses of ketamine stimulate psychosis in schizophrenia. Neuropsychopharmacology 13:9-19

Luby ED, Cohen BD, Rosenbaum G, Gottlieb JS, Kelley R (1959): Study of a new schizophrenomimetic drug-sernyl. Arch Neurol Psychiatry 81:363-369

Malhotra AK, Pinals DA, Weingartner H, Sirocco K, Missar CD, Pickar D, Breier A (1996): NMDA receptor function and human cognition: The effects of ketamine in healthy volunteers. Neuropsychopharmacology 14:301-307

Moretti RJ, Hassan SZ, Goodman LI, Meltzer HY (1984): Comparison of ketamine and thiopental in healthy volunteers: Effects on mental status, mood, and personality. Anesth Analg 63:1087-1096
Olney JW, Labruyere J, Price MT (1989): Pathological changes induced in cerebrocortical neurons by phenylcyclidine and related drugs. Science 244:1360-1362

Olney JW, Farber NB (1995): Glutamate receptor dysfunction and schizophrenia. Arch Gen Psychiatry 52:998-1007

Overall JE, Gorham DR (1962): The brief psychiatric rating scale. Psychol Rep 10:799-812

Oye I, Hustveit O, Moberg ER, Pausen O, Skoglund LA (1991): The chiral forms of ketamine as probes for NMDA receptor function in humans. In Kameyama T, Nabeshima T, Domino EF (eds), NMDA Receptor Related Agents: Biochemistry, Pharmacology, and Behavior. Ann Arbor, Michigan, NPP Books, pp 381-389

Pandit SK, Kothary SP, Kumar SM (1980): Low dose intravenous infusion technique with ketamine. Anaesthesia 35:669-675

Rosenbaum G, Cohen BD, Luby ED, Gottlieb JS, Yelen D (1959): Comparison of Sernyl with other drugs. A. M. A. Arch Gen Psychiatry 1:651-666

Rothman S (1988): Noncompetitive N-methyl-D-aspartate antagonists affect multiple ionic currents. J Pharmacol Exp Ther 246:137-142

Schorn TOF, Whitman JG (1980): Are there long-term effects of ketamine on the central nervous system? Br J Anaesth 52:967-968

Smith DJ, Azzaro AJ, Zaldivar SB, Palmer S, Lee HS (1981): Properties of the optical isomers and metabolites of ketamine on the high affinity transport and catabolism of monoamines. Neuropharmacology 20: 391-396

Smith DJ, Pekoe GM, Martin LL, Coalgate B (1980): The interaction of ketamine with the opiate receptor. Life Sci 26:789-795

Spitzer RL, Williams JBW, Gibbon M, First MB (1990): Structured clinical interview for DSM-III-R-patient edition (SCID-P, Version 1.0). Washington, DC: American Psychiatric Press

Weingartner HJ, Hommer D, Lister RG, Thompsom K, Wolkowitz O (1992): Selective effects of triazolam on memory. Psychopharmacology 106:341-345

Weingartner H, Grafman J, Boutelle W, Kayne W, Martin PR (1983a): Forms of memory failure. Science 221:380-382

Weingartner H, Rudorfer MV, Buchsbaum MS, Linnoila M (1983b): Effects of serotonin on memory impairments produced by ethanol. Science 221:472-473

Weingartner H, Langer D, Grice J, Rapoport J (1982): Acquisition and retrieval of information in amphetaminetreated hyperactive children. Psychiatry Res 6:21-29 